\title{
Study of Dye-Sensitized Solar Cells by Scanning Electron Micrograph Observation and Thickness Optimization of Porous $\mathrm{TiO}_{2}$ Electrodes
}

\author{
Seigo Ito, ${ }^{1,2}$ Mohammad K. Nazeeruddin, ${ }^{2}$ Shaik M. Zakeeruddin, ${ }^{2}$ Peter Péchy, \\ Pascal Comte, ${ }^{2}$ Michael Grätzel, ${ }^{2}$ Takaki Mizuno, ${ }^{3}$ Atsushi Tanaka, ${ }^{3}$ and Tsuguo Koyanagi ${ }^{3}$ \\ ${ }^{1}$ Department of Electrical Engineering and Computer Sciences, Graduate School of Engineering, \\ University of Hyogo, 2167 Shosha, Himeji, Hyogo 671-2280, Japan \\ ${ }^{2}$ Laboratoire de Photonique et Interfaces, Institut des Sciences et Ingénierie Chimiques, \\ École Polytechnique Fédérale de Lausanne (EPFL), Station 6, CH-1015 Lausanne, Switzerland \\ ${ }^{3}$ New Business Research Center, JGC Catalysts and Chemicals Ltd., 13-2 Kitaminato-Machi, \\ Wakamatsu-Ku, Kitakyuushu, Fukuoka 808-0027, Japan
}

Correspondence should be addressed to Seigo Ito, itou@eng.u-hyogo.ac.jp

Received 13 April 2009; Accepted 12 May 2009

Recommended by Mohamed Abdel-Mottaleb

In order to improve the photoenergy conversion efficiency of dye-sensitized solar cells (DSCs), it is important to optimize their porous $\mathrm{TiO}_{2}$ electrodes. This paper examines the surface and cross-sectional views of the electrodes using scanning electron micrography. Two types of samples for cross-sectional viewing were prepared by mechanically breaking the substrate and by using an Ar-ion etching beam. The former displays the surface of the $\mathrm{TiO}_{2}$ particles and the latter shows the cross-section of the $\mathrm{TiO}_{2}$ particles. We found interesting surface and cross-sectional structures in the scattering layer containing the $400 \mathrm{~nm}$ diameter particles, which have an angular and horned shape. The influence of $\mathrm{TiO}_{2}$ particle size and the thickness of the nanocrystalline$\mathrm{TiO}_{2}$ electrode in DSCs using four kinds of sensitizing dyes (D149, K19, N719 and Z907) and two kinds of electrolytes (acetonitrilebased and ionic-liquid electrolytes) are discussed in regards to conversion efficiency, which this paper aims to optimize.

Copyright (C) 2009 Seigo Ito et al. This is an open access article distributed under the Creative Commons Attribution License, which permits unrestricted use, distribution, and reproduction in any medium, provided the original work is properly cited.

\section{Introduction}

Dye-sensitized solar cells (DSCs) have recently been developed as a cost-effective photovoltaic system due to their lowcost materials and facile processing [1-4]. The production of DSCs involves chemical and thermal processes but no vacuum is involved. Therefore, DSCs can be fabricated without using expensive equipment. The use of dyes and nanocrystalline $\mathrm{TiO}_{2}$ is one of the most promising approaches to realize both high performance and low cost. A high light-toelectricity conversion efficiency can be obtained from a large surface area of porous $\mathrm{TiO}_{2}$ electrodes on which the dyes can be sufficiently adsorbed.

In order to fabricate DSC devices characterized by high efficiency ( $>10 \%)$ and/or long-term stability, further understanding and state-of-art techniques are necessary. The key points of the DSC mechanism are as follows

(1) Ultrafast electron injection from the dye to the $\mathrm{TiO}_{2}$ electrode ( $<20$ femtoseconds) [5].

(2) Fast dye regeneration via reduction by I- (100 nanoseconds without voltage bias) [6].

(3) The very long electron lifetime in the $\mathrm{TiO}_{2}$ electrode to $\mathrm{I}_{3}^{-}$( $>0.1$ second below $0.7 \mathrm{~V}$ forward bias) [7].

(4) The large roughness factor of the $\mathrm{TiO}_{2}$ electrode $(>1600)[8]$.

(5) The diode effect of $\mathrm{Ru}$ dye on the $\mathrm{TiO}_{2}$ electrode [8].

(6) Photon adsorption controlled by the thickness of the $\mathrm{TiO}_{2}$ layers (transparent layer, $d=20 \mathrm{~nm}, 12-$ $14 \mu \mathrm{m}$ thickness; scattering layer, $d=400 \mathrm{~nm}, 4-5 \mu \mathrm{m}$ thickness) [9]. 


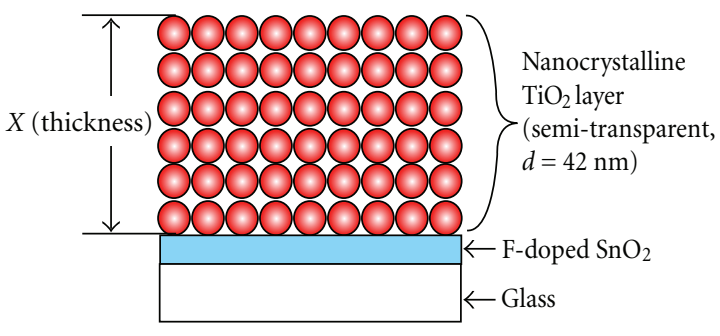

(a)

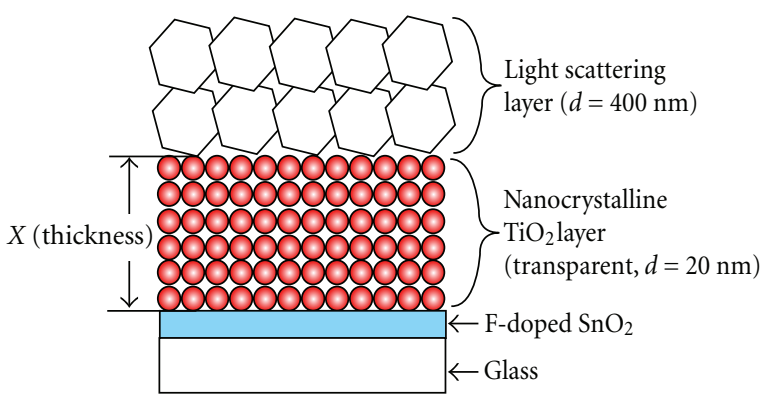

(b)

FIGURE 1: Structure of DSC with single-layer (a) and double-layer (b) structures of nanocrystalline- $\mathrm{TiO}_{2}$ electrodes. X's in figures show the thickness of nanocrystalline- $\mathrm{TiO}_{2}$ electrodes that was varied for the optimization of high-efficiency DSC (Figures 5, 6 and 7).

(7) A high-activity Pt counter electrode for $\mathrm{I}^{-} / \mathrm{I}_{3}^{-}$redox $(<8 \Omega)[10]$.

Each point listed above is necessary for high-efficiency DSCs. One of the key materials is the $\mathrm{TiO}_{2}$ electrode, which has been fabricated by using sol-gel screen printing. With this method, the $\mathrm{TiO}_{2}$ particle size and the thickness of the nanocrystalline- $\mathrm{TiO}_{2}$ layer (" $\mathrm{X}$ " in Figure 1) can be varied, allowing for control of the photovoltage and photocurrent. Thus, we can optimize the design of the porous $\mathrm{TiO}_{2}$ electrode, the sensitizing dye and the electrolyte.

In this paper, we study the surface and cross-sectional structure of double-layered porous $\mathrm{TiO}_{2}$ electrodes by SEM observation. We found significant differences between the SEM images of the original structure composed of submicron particles and those of a structure composed of a mixture of submicron particles and nanoparticles. The two types of cross-sectional samples were prepared either by mechanically breaking the substrate or using an Ar-ion beam etching technique, resulting in confirmation of the significant difference in the appearance of the two samples and the observation of the interesting angular and horned structure of the $400 \mathrm{~nm}$ diameter particles in the cross-sectional view. Subsequently, the effect of the $\mathrm{TiO}_{2}$ particle size $(d=20 \mathrm{~nm}$, $42 \mathrm{~nm}$ and $400 \mathrm{~nm}$ ) and the thickness of the nanocrystalline$\mathrm{TiO}_{2}$ electrode on the photovoltaic properties of DSCs are evaluated with four kinds of sensitizing dyes (D149, K19, N719 and Z907) and two kinds of electrolytes (acetonitrile (AcCN) based and ionic-liquid (IL) electrolytes) in order to achieve high conversion efficiency.

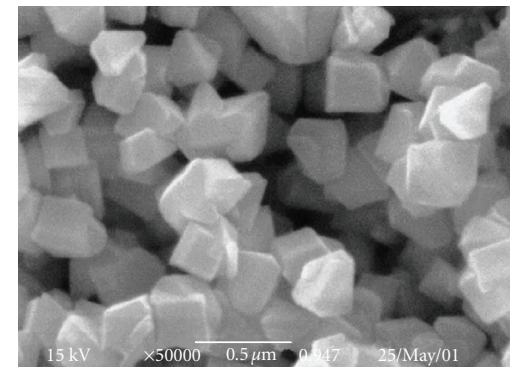

(a)

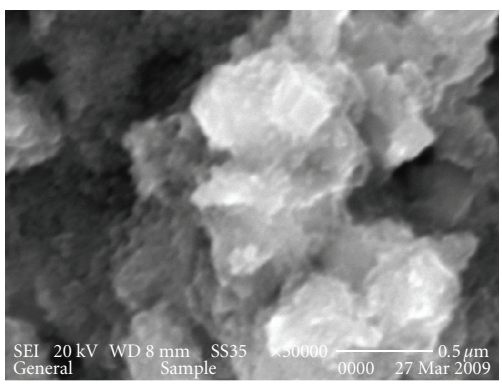

(b)

FIGURE 2: SEM images of the surface of $\mathrm{TiO}_{2}$ submicron particles (400C, JGC-CCIC) (a) and a mixture of $\mathrm{TiO}_{2}$ submicronparticles and nanoparticles (PST-400C, JGC-CCIC) (b). Magnification of each view is 50,000 times.

\section{Experimental}

2.1. Materials. Three kinds of screen-printing paste containing different $\mathrm{TiO}_{2}$ (anatase) particles (20 nm [9], $42 \mathrm{~nm}$ [11] and $400 \mathrm{~nm}$ [9]) were prepared by previously reported procedures. For SEM observations, we used $\mathrm{TiO}_{2}$ materials from JGC Catalysis and Chemicals Ltd. (JGCCCIC, Japan). The syntheses of cis-Ru-di(thiocyanato)N,N' -bis (2,2' -bipyridyl-4-carboxylic acid-4'-tetrabutylammonium carboxylate) (N-719) [12], cis-(SCN) 2 (4, 4' -dicarboxylic acid-2,2'-bipyridine) (4, 4' -dinonyl-2, 2' -bipyridine) (Z907) [13], Ru((4,4-dicarboxylic acid-2, 2' -bipyridine) (4, 4'-bis(p-hexyloxystyryl)-2,2 bipyridine) (NCS)2 (K19) [14] and indoline dye (D149) [15] have been reported in previous papers. The chromatographic purification of the $\mathrm{Ru}$ dyes was carried out on a column of Sephadex LH-20 using a previously reported procedure $[9,12]$.

2.2. Porous $\mathrm{TiO}_{2}$ Electrodes. To prepare the working electrodes, the fluorine-doped tin oxide (FTO) glass that was used as the current collector (Nippon Sheet Glass, Solar, $4 \mathrm{~mm}$ thickness) was first cleaned in a detergent solution using an ultrasonic bath for 15 minutes and then rinsed with water and ethanol. After treatment in an $\mathrm{UV}_{-} \mathrm{O}_{3}$ system for 18 minutes, the FTO glass plates were immersed in a $40 \mathrm{mM}$ aqueous solution of $\mathrm{TiCl}_{4}$ at $70^{\circ} \mathrm{C}$ for 30 minutes and washed with water and ethanol.

A layer of nanocrystalline- $\mathrm{TiO}_{2}$ paste was coated onto the FTO glass plates by screen printing and kept in a clean box for 3 minutes so that the paste could settle to 
reduce the irregularity of the surface and then dried for 6 minutes at $125^{\circ} \mathrm{C}$. This screen-printing procedure with the paste (coating, storing and drying) was repeated to obtain a working electrode of appropriate thickness [9]. By adjusting the thickness of the $\mathrm{TiO}_{2}$ pastes, the $\mathrm{TiO}_{2}$ electrodes were designed as shown in Figure 1. The porous $\mathrm{TiO}_{2}$ layers of $20 \mathrm{~nm}$ [9], $42 \mathrm{~nm}$ [11] and $400 \mathrm{~nm}$ [9] were transparent, semitransparent and scattering, respectively. For the scattering layer, two coatings of macrocrystalline- $\mathrm{TiO}_{2}$ paste were deposited by screen printing, resulting in a lightscattering $\mathrm{TiO}_{2}$ layer of $4-5 \mu \mathrm{m}$ thickness containing $400 \mathrm{~nm}$ sized anatase particles. The electrodes coated with the $\mathrm{TiO}_{2}$ pastes were gradually heated under an air flow at $325^{\circ} \mathrm{C}$ for 5 minutes, at $375^{\circ} \mathrm{C}$ for 5 minutes, at $450^{\circ} \mathrm{C}$ for 15 minutes and $500^{\circ} \mathrm{C}$ for 15 minutes.

The sintered $\mathrm{TiO}_{2}$ film was treated with $40 \mathrm{mM}$ $\mathrm{TiCl}_{4}$ solution as described above, rinsed with water and ethanol and sintered again at $500^{\circ} \mathrm{C}$ for 30 minutes. After cooling to $80^{\circ} \mathrm{C}$, the $\mathrm{TiO}_{2}$ electrode was immersed in a $0.5 \mathrm{mM}$ dye solution in a mixture of acetonitrile and tert-butyl alcohol (v/v: $1: 1)$ and kept at room temperature for 20-24 hours (Ru dyes) or 4 hours (D149 with $1.0 \mathrm{mM}$ chenodeoxy cholic acid) to complete the sensitizer uptake.

2.3. Pt Counter Electrodes. To prepare the counter electrode, a hole was drilled in the FTO glass (LOF Industries, TEC $15 \Omega / \square, 2.2 \mathrm{~mm}$ thickness) by sand blasting. The perforated glass sheet was washed with $\mathrm{H}_{2} \mathrm{O}$ as well as with a $0.1 \mathrm{M} \mathrm{HCl}$ solution in ethanol and cleaned by ultrasound in an acetone bath for 10 minutes. After removing residual organic contaminants by heating in air for 15 minutes at $400^{\circ} \mathrm{C}$, the Pt catalyst was deposited on the FTO glass by coating with a drop of $\mathrm{H}_{2} \mathrm{PtCl}_{6}$ solution (3 mg Pt in $1 \mathrm{~mL}$ ethanol) and repeating the heat treatment at $400^{\circ} \mathrm{C}$ for 15 minutes.

2.4. DSC Assembly. The dye-covered $\mathrm{TiO}_{2}$ electrode and Pt counter electrode were assembled into a sandwich-type cell and sealed with a hot-melt gasket of $25 \mu \mathrm{m}$ thickness made of the ionomer Surlyn1702 or liner low density polyethylene Bynel4164 (DuPont) on a heating stage. A drop of the electrolyte was put on the hole in the back of the counter electrode. The acetonitrile $(\mathrm{AcCN})$ based electrolyte for N719 was $0.60 \mathrm{M}$ BMII, $0.03 \mathrm{M} \mathrm{I}_{2}, 0.10 \mathrm{M}$ guanidinium thiocyanate and $0.50 \mathrm{M}$ 4-tert-butylpyridine in a mixture of acetonitrile and valeronitrile (v/v: $85: 15)[8-$ 10]. The ionic-liquid (IL) electrolyte for Z907 and K19 was $0.2 \mathrm{M} \mathrm{I}_{2}, 0.5 \mathrm{M} \mathrm{NMBI}$ and $0.1 \mathrm{M}$ GuNCS in a mixture of PMII/EMINCS (v/v: 13:7) [14]. The AcCN-based electrolyte for D149 was $0.10 \mathrm{M}$ lithium iodide, $0.60 \mathrm{M}$ butylmethylimidazolium iodide, $0.05 \mathrm{M} \mathrm{I}_{2}$ and $0.05 \mathrm{M}$ 4-tert-butylpyridine in AcCN:valeronitrile (v/v: $85: 15)$ ) [16]. The IL electrolyte for D149 was $0.20 \mathrm{M} \mathrm{I}_{2}$ in 1-methyl-3-propylimidazolium iodide, 1-ethyl-3-methylimidazolium bis((trifluoromethyl) sulfonyl) imide and 1-ethyl-3-methylimidazolium triflate $(\mathrm{v} / \mathrm{v} / \mathrm{v}: 2: 1: 1)[16]$.

The cell was placed in a small vacuum chamber for a few seconds to remove the inside air. Exposing it again to ambient pressure caused the electrolyte to be driven into the cell. Finally, the hole was sealed using a hot-melt liner low density polyethylene film (Bynel 4164, $35 \mu \mathrm{m}$ thickness, Du-Pont) and a cover glass ( $0.1 \mathrm{~mm}$ thickness). In order to have good electrical contact between the connections and the photovoltaic measurement equipment, the edge of the FTO outside of the cell was scraped slightly with sandpaper or a file. A solder (Cerasolza, Asahi Glass) was applied on each side of the FTO electrodes.

2.5. Measurements. Photovoltaic measurements employed an AM 1.5 solar simulator $\left(100 \mathrm{~mW} \mathrm{~cm}^{-2}\right)$. Masks made of black plastic tape were attached on the Arctop filter to reduce the scattering of light [17]. The intensity of the simulated light was calibrated by using a reference $\mathrm{Si}$ photodiode equipped with an IR cutoff filter (KG-3, Schott) in order to reduce the mismatch in the region of 350-750 nm between the simulated light and AM 1.5 to less than $2 \%$ [18]. I-V curves were obtained by applying an external bias voltage to the cell and measuring the generated photocurrent with a digital source meter (Keithley 2400, Keithley Instruments).

\section{Results and Discussions}

3.1. SEM Observation of Nanocrystalline-TiO $\mathrm{O}_{2}$ Porous Electrodes. Figure 2(a) shows the SEM images of submicron $\mathrm{TiO}_{2}$ particles that were used in the light-scattering layer (Figure 1(b)). The particles were a pyramid-like angular shape. The light-scattering $\mathrm{TiO}_{2}$ layer was a mixture of nanosized and submicron $\mathrm{TiO}_{2}$ particles [9]. In the SEM observations, the angular shape of the submicron $\mathrm{TiO}_{2}$ particles could not be seen in the light-scattering layer (Figure 2(b)). The submicron $\mathrm{TiO}_{2}$ particles were surrounded by nanoparticles. The outline of the angular shape can be seen through the surrounding nanoparticles.

Figure 3 shows cross-sectional SEM images of a porous $\mathrm{TiO}_{2}$ electrode that was prepared by breaking the substrate with a glass cutter. It is noticeable that the electrode has a double-layered structure, as illustrated in Figure 1(b). The magnified view of the light-scattering layer (Figure 3(b)) is similar to Figure 2(b); the submicron particles were coated by nanoparticles in the cross-sectional view of a sample prepared by mechanically breaking the substrate.

Figure 4 shows the cross-sectional images of a nanocrystalline- $\mathrm{TiO}_{2}$ porous electrode prepared by polishing with an Ar-ion beam (the preparation and observation of the samples were done by KOBELCO Research Institute, Inc., Japan). The observed nanocrystalline- $\mathrm{TiO}_{2}$ porous electrode has a double-layered structure on a glass substrate similar to Figure $1(\mathrm{~b})$. The nanocrystalline- $\mathrm{TiO}_{2}$ layer is smooth and flat, while the submicroncrystalline- $\mathrm{TiO}_{2}$ layer is rough due to the large particle size (Figure $4(\mathrm{a})$ ). The nanocrystalline- $\mathrm{TiO}_{2}$ layer appears very homogeneous at 5000 -times magnification (Figure 4(b)). At 50000 times magnification (Figure 4(c)), small cracks can be seen in the layer due to shrinkage caused by the heating procedure. At 200000 times magnification, the nanoparticles can be 


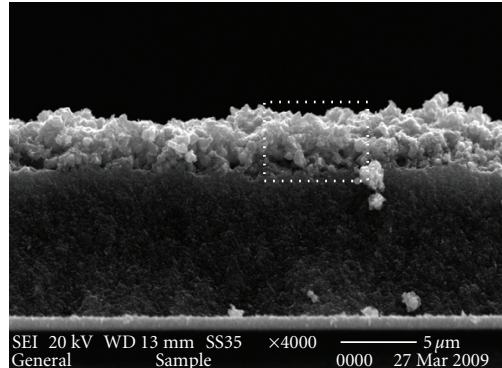

(a)

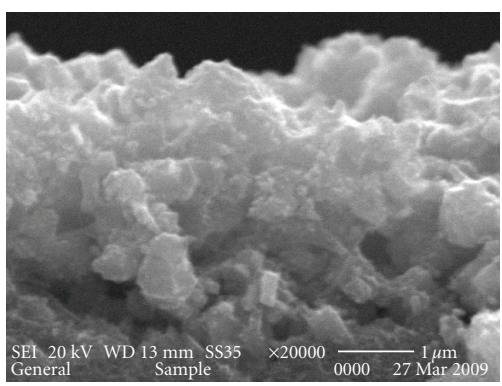

(b)

Figure 3: Cross-sectional views of a double-layer electrode prepared by mechanically breaking the substrate. The white dotted quadrangle in Figure 3(a) indicates the zoomed-in area shown in Figure 3(b).

observed (Figure 4(d)), but the image is not clear because no metal was deposited by spattering in order to observe them. Figure 4(e) shows the cross-section of the light-scattering layer by submicroncrystalline- $\mathrm{TiO}_{2}$ particles. The material of this layer is a mixture of $90 \%$ of submicroncrystalline$\mathrm{TiO}_{2}$ particles and $10 \%$ of nanocrystalline- $\mathrm{TiO}_{2}$ particles [9]. We can see the exact cross-sectional view of the submicroncrystalline- $\mathrm{TiO}_{2}$ particles (Figure $4(\mathrm{f})$ ). The size of the cross-sectioned submicron crystals is between $100 \mathrm{~nm}$ and $500 \mathrm{~nm}$. This size distribution is due to the Ar-ion beam etching, which cut the crystal at the center and/or the edge. It is surprising that the structure of the submicroncrystalline$\mathrm{TiO}_{2}$ particles is rather complicated (angular and horned) in the cross-sectional view, which cannot be observed in the SEM images of Figure 2(a).

3.2. I-V Curves with Variation of $\mathrm{TiO}_{2}$ Thickness. Figure 5 shows the I-V curves of the DSCs with double-layer $\mathrm{TiO}_{2}(d=20 \mathrm{~nm}$ and $400 \mathrm{~nm}$ ) electrodes (Figure 1(b)). The thickness of the nanocrystalline- $\mathrm{TiO}_{2}$ layer was adjusted between $2.8 \mu \mathrm{m}$ to $17.4 \mu \mathrm{m}$. The sensitizing dye was a Ru dye (N719), and the electrolyte was an AcCN-based electrolyte. It was observed that the thicker layer gave higher photocurrent and lower photovoltage. On the other hand, the thinner layer gave lower photocurrent and higher photovoltage. This is a typical phenomenon in DSCs regardless of the kind of particles and dyes. In the next sections, we discuss the photovoltaic characteristics for two sizes of $\mathrm{TiO}_{2}$ nanoparticles ( $d=42 \mathrm{~nm}$ and $20 \mathrm{~nm})$.
3.3. Single-Layer Electrodes. Figure 6 shows the photovoltaic characteristics of single-layer electrodes with a semitransparent layer of $42 \mathrm{~nm} \mathrm{TiO}_{2}$ particles (Figure 1(a)). The combinations of sensitizing dyes and electrolytes were $\langle\mathrm{Ru}$ dye (N719)/AnCN-based electrolyte $\rangle$ and $\langle$ Ru dye (Z907)/IL electrolyte).

For both combinations of dye and electrolyte, the open-circuit photovoltage (Voc) decreased linearly with increasing thickness of the nanocrystalline- $\mathrm{TiO}_{2}$ electrode (Figure 6(a)).

However, the behavior of the short-circuit photocurrent density (Jsc) (Figure 6(b)) was different for the electrolytes. For the AcCN-based electrolyte, the Jsc increased and became saturated with increasing thickness. On the other hand, the $J s c$ for the IL electrolyte reached a maximum around $14 \mu \mathrm{m}$. At the thin $\mathrm{TiO}_{2}$ electrode ( $4 \mu \mathrm{m}$ thickness), the values of $J s c$ for the AcCN-based $\left(11.8 \mathrm{~mA} \mathrm{~cm}^{-2}\right)$ and IL $\left(10.5 \mathrm{~mA} \mathrm{~cm}^{-2}\right)$ electrolytes were similar; the difference was only $12 \%\left(1.3 \mathrm{~mA} \mathrm{~cm}^{-2}\right)$. Upon increasing the thickness, the difference increased to $42 \%$ for the $21 \mu \mathrm{m}$ thick films. This arises from the high viscosity and slow $\mathrm{I}^{-} / \mathrm{I}_{3}^{-}$diffusion in the IL electrolyte [16]. The redox couple $\left(\mathrm{I}^{-} / \mathrm{I}_{3}^{-}\right)$can diffuse readily across the thin nanocrystalline- $\mathrm{TiO}_{2}$ layer and sustain the low photocurrent. However, transport is impaired in thicker nanocrystalline electrode films where larger photocurrents must be sustained. By contrast, the viscosity of $\mathrm{AcCN}$ is so low that high photocurrent can be supported even for thick nanocrystalline- $\mathrm{TiO}_{2}$ layers.

The fill factor (FF) was not affected by variations in the thickness of the nanocrystalline- $\mathrm{TiO}_{2}$ layer (Figure 6(c)).

Consequently, the conversion efficiency reached a maximum (Figure 6(d)). Nevertheless, the viscosity and the diffusion coefficient of $\mathrm{I}^{-} / \mathrm{I}_{3}^{-}$differed by a factor of 100 [16], the AcCN-based and IL electrolytes gave peaks in the same position for the 14-16 $\mu \mathrm{m}$ thickness.

3.4. Double-Layer Electrodes. Figure 7 shows the photovoltaic characteristics of the double-layer electrodes (Figure 1(b)). The particle sizes for the transparent and lightscattering layers were $20 \mathrm{~nm}$ and $400 \mathrm{~nm}$, respectively. In this paper, the thickness of the transparent layer $(d=20 \mathrm{~nm}$; "X" in Figure 1(b)) was varied. Four combinations of sensitizing dyes and electrolytes were used: $\langle\mathrm{Ru}$ dye (N719)/AnCNbased electrolyte〉, 〈Ru dye (K19)/IL electrolyte〉, 〈organic dye (D149)/AnCN-based electrolyte〉 and 〈organic dye (D149)/IL electrolyte $>$.

In all cases, Voc decreased linearly with increasing the thickness of the nanocrystalline- $\mathrm{TiO}_{2}$ electrode (Figure $7(\mathrm{a})$ ). This phenomenon was the same as that of the single-layer system (Figure 6(a)). It was remarkable that the highest $V o c$ was over $900 \mathrm{mV}$ for the nanocrystalline$\mathrm{TiO}_{2}$ electrode $(3 \mu \mathrm{m})$ using Ru dye (N719) and AcCN-based electrolyte.

Figure 7(b) shows the differences in the behavior of Jsc in relation to the nanocrystalline- $\mathrm{TiO}_{2}(d=20 \mathrm{~nm})$ thickness (Figure 1(b)) between AcCN-based and IL electrolytes, which is similar to the phenomenon observed for the singlelayer electrode $(d=42 \mathrm{~nm}$, Figure 6(b)). Using the AcCNbased electrolyte, the $J s c$ increased and became saturated 


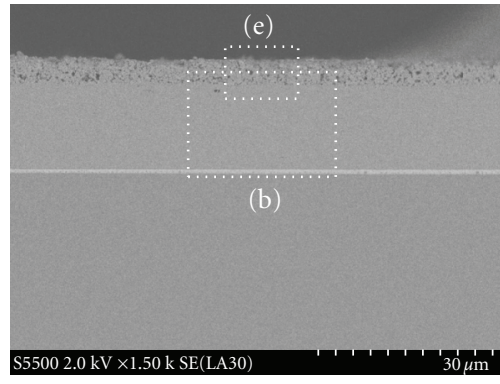

(a)

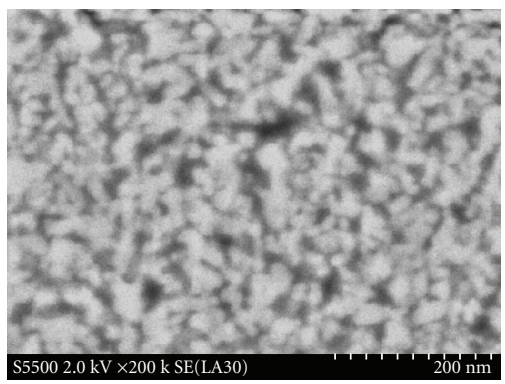

(d)

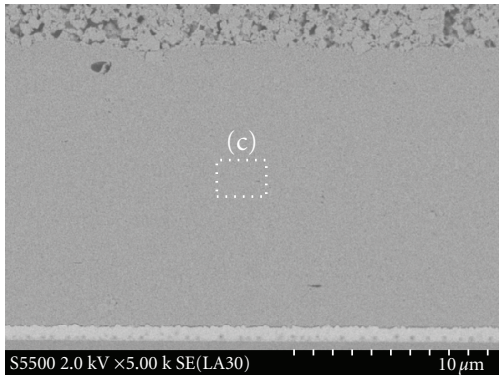

(b)

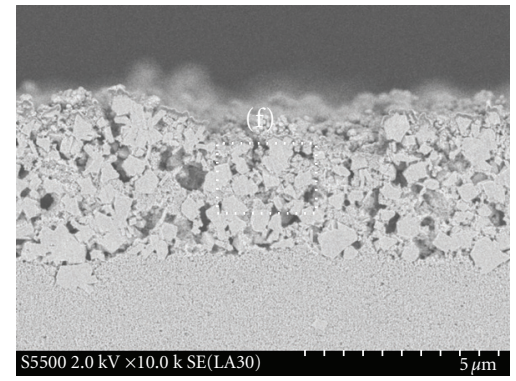

(e)

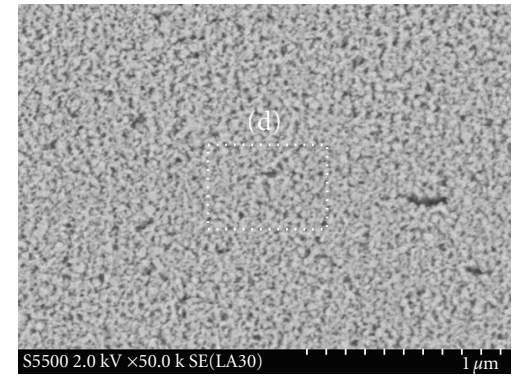

(c)

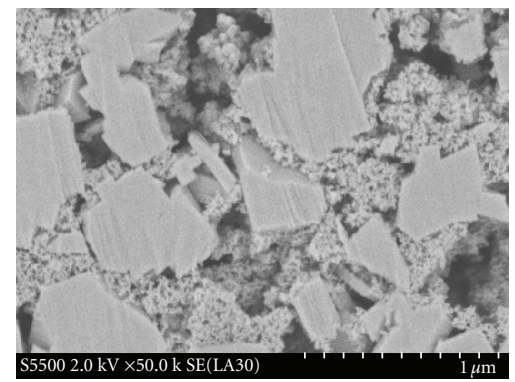

(f)

Figure 4: Cross-sectional SEM images of a porous double-layered $\mathrm{TiO}_{2}$ electrode polished with an Ar-ion beam (nanocrystalline-TiO 2 layer: $14 \mu \mathrm{m}$ thick; submicron crystalline- $\mathrm{TiO}_{2}$ layer: $5 \mu \mathrm{m}$ thick). (a) is the most zoomed-out image. White dotted quadrangles show the zoomed-in area for the other images.

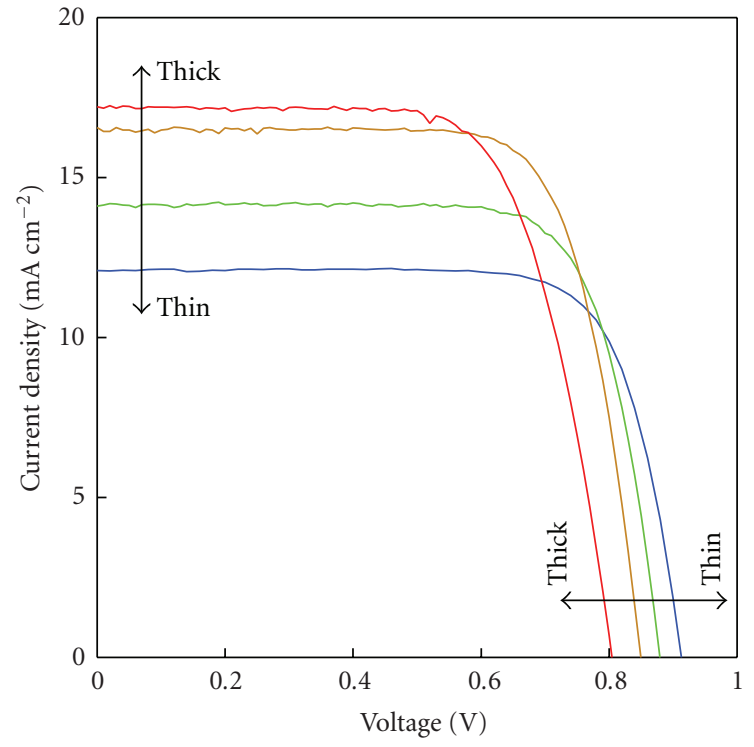

FIGURE 5: Photo I-V curves in relation to the thickness of doublelayer nanocrystalline- $\mathrm{TiO}_{2}$ electrodes (as shown in Figure 1(b)) with Ru dye (N719) and AcCN-based electrolyte.

with increasing thickness. On the other hand, using the IL electrolyte, the $J s c$ had a peak at a thickness of around $6 \mu \mathrm{m}$. The optimal thickness for the $20 \mathrm{~nm}$ particles (Figure 7(b)) was half that obtained for the $42 \mathrm{~nm}$ particles (Figure 6(b)). The larger particles $(d=42 \mathrm{~nm}$, Figure $6(\mathrm{~b}))$ produced larger pores into which the redox couple $\left(\mathrm{I}^{-} / \mathrm{I}_{3}^{-}\right)$could diffuse more effectively than into the smaller pores created by the smaller particles $(d=20 \mathrm{~nm})$. Therefore, the larger particles gave a $J s c$ peak at a larger thickness than the smaller particles.

The FF was not greatly affected by variations in the thickness of the nanocrystalline- $\mathrm{TiO}_{2}$ layer (Figure $7(\mathrm{c})$ ). In the case of the organic dye (D149) with IL electrolyte, however, the FF decreased as a result of the high photocurrent and the low diffusion coefficient of the redox couple.

Consequently, the conversion efficiency reached a maximum (Figure 7(d)). The AcCN-based and IL electrolytes gave peaks at $14 \mu \mathrm{m}$ and $6 \mu \mathrm{m}$ thickness, respectively. The important point is that the position of the peaks was unrelated to the nature of the Ru dye and the organic dye, in spite of the 4-fold difference between their absorption coefficients (N719: 13,900 M-1 $\mathrm{cm}^{-1}, \mathrm{~K} 19: 18,200 \mathrm{M}^{-1} \mathrm{~cm}^{-1}$, D149: $\left.68,700 \mathrm{M}^{-1} \mathrm{~cm}^{-1}\right)$. At first, we expected that the organic dye would yield the highest efficiency when the thickness of the nanocrystalline- $\mathrm{TiO}_{2}$ layer was small; however, the peak of efficiency was determined by the electrolyte and the particle size, not by the type of sensitizer.

\section{Conclusions}

The structure of the cross-section of the double-layered $\mathrm{TiO}_{2}$ electrode, which was prepared by Ar-ion beam etching, has been observed by SEM for the first time. We confirmed the difference between the cross-sectional structures prepared by mechanically breaking the substrate and Ar-ion beam 


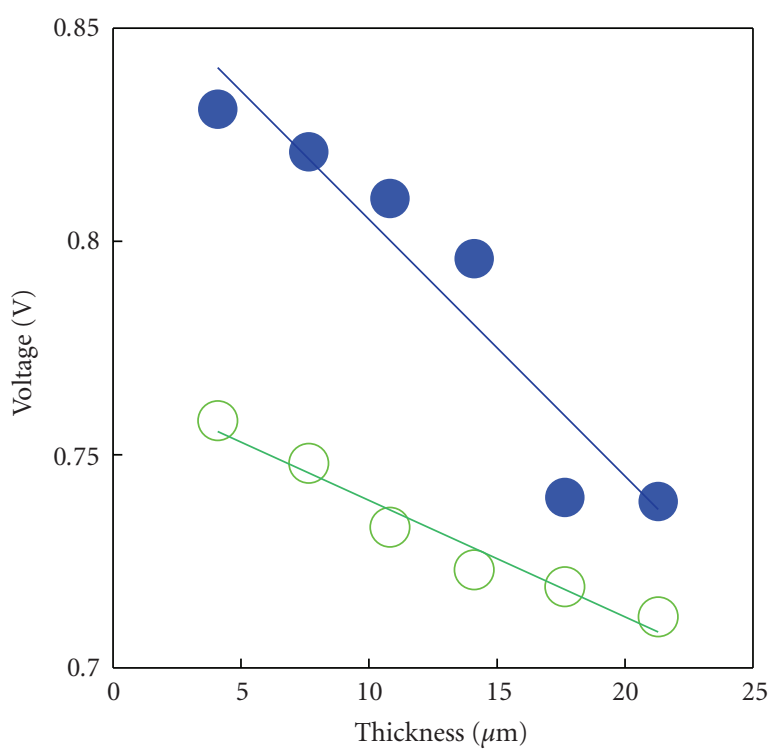

(a)

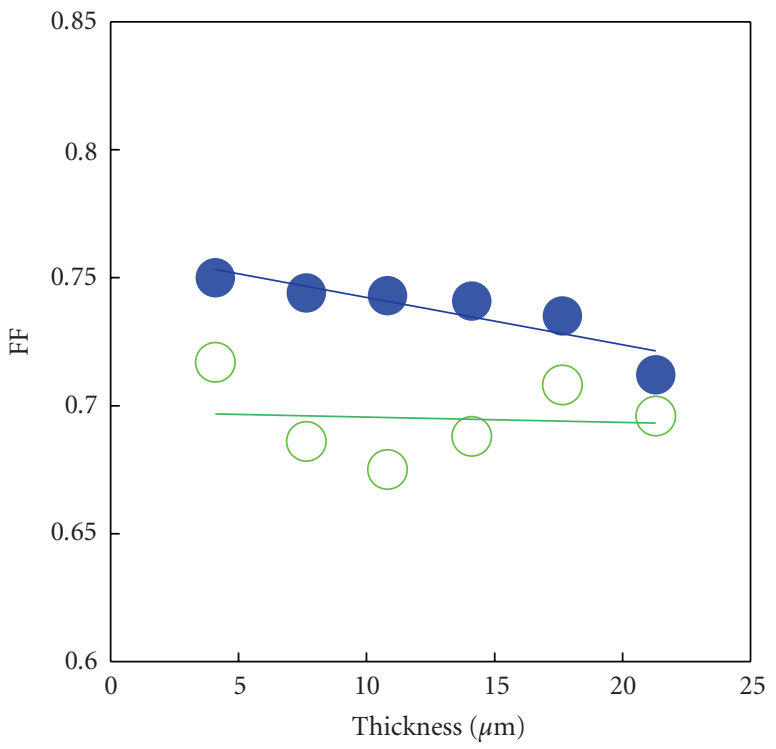

(c)

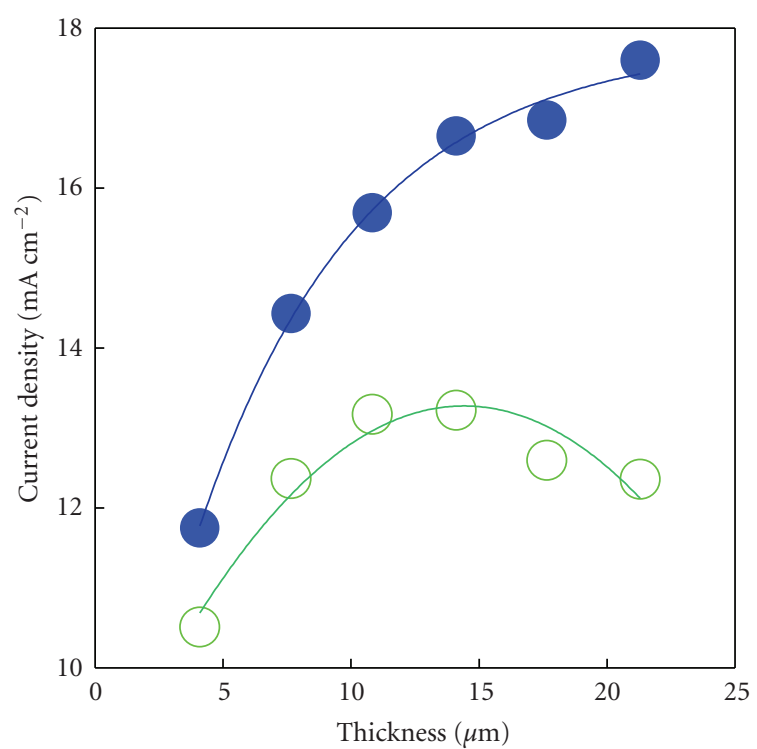

(b)

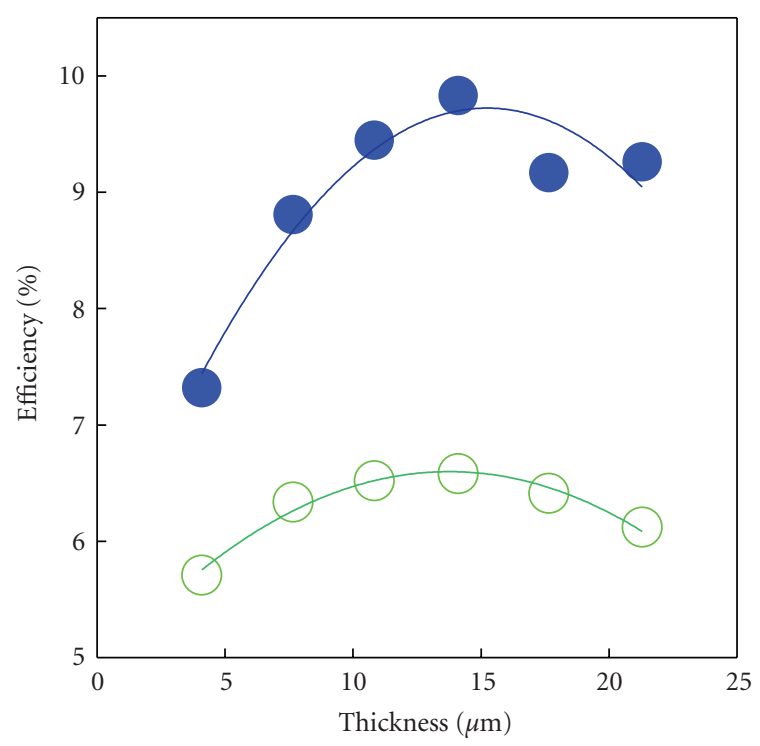

(d)

Figure 6: Photovoltaic characteristics related to the thickness of nanocrystalline- $\mathrm{TiO}_{2}(d=42 \mathrm{~nm}$ ) layers of single-layer electrodes (as shown in Figure 1(a)): N719-sensitized solar cells using AcCN-based electrolytes (solid circles); Z907-sensitized solar cells using IL electrolytes (open circles).

etching and observed the unique structure of the $400 \mathrm{~nm}$ $\mathrm{TiO}_{2}$ particles with respect to the light-scattering effect.

In order to optimize the design of DSCs for maximal conversion efficiency, the $\mathrm{TiO}_{2}$ particle size and the thickness of the nanocrystalline- $\mathrm{TiO}_{2}$ layer were varied and tested with several sensitizing dyes and electrolytes. For the singlelayer electrodes (semitransparent, $d=42 \mathrm{~nm}$ ), the maximal efficiencies were $6.6 \%$ at $14 \mu \mathrm{m}$ and $9.9 \%$ at $16 \mu \mathrm{m}$ with $\langle\mathrm{Z} 907 / \mathrm{IL}\rangle$ and $\langle\mathrm{N} 719 / \mathrm{AcCN}\rangle$, respectively. For the doublelayer electrodes (transparent layer: $d=20 \mathrm{~nm}$; lightscattering layer: $d=400 \mathrm{~nm}$ ), the maximal efficiencies were $7.0 \%$ at $6 \mu \mathrm{m}, 6.3 \%$ at $6 \mu \mathrm{m}, 10.2 \%$ at $14 \mu \mathrm{m}$ and
9.0\% at $14 \mu \mathrm{m}$ with $\langle\mathrm{K} 19 / \mathrm{IL}\rangle,\langle\mathrm{D} 149 / \mathrm{IL}\rangle,\langle\mathrm{N} 719 / \mathrm{AcCN}\rangle$ and $\langle\mathrm{D} 149 / \mathrm{AcCN}\rangle$, respectively. The optimal thickness of the nanocrystalline- $\mathrm{TiO}_{2}$ layer depends on the electrolyte and $\mathrm{TiO}_{2}$ particle size but not on the absorption coefficient of the dye.

From these experimental results, we can estimate the conversion efficiency of a DSC for an ideal case where Voc, $J s c$ and $\mathrm{FF}$ attain their maximal values. The best values were a Voc of $900 \mathrm{mV}$ (Figure 7(a)), a Jsc of $20 \mathrm{mAcm}^{-2}$ (Figure 7(b)) and an FF of 0.77 (Figure 7(c)). Using these values, the ideal conversion efficiency reaches $13.9 \%$. In order to obtain this value, we need to use a dye with 


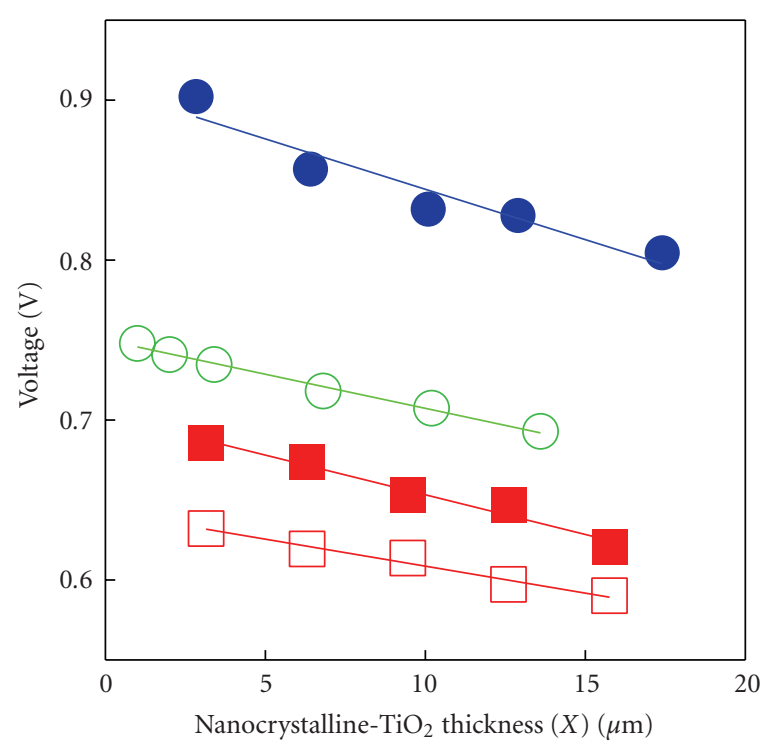

(a)

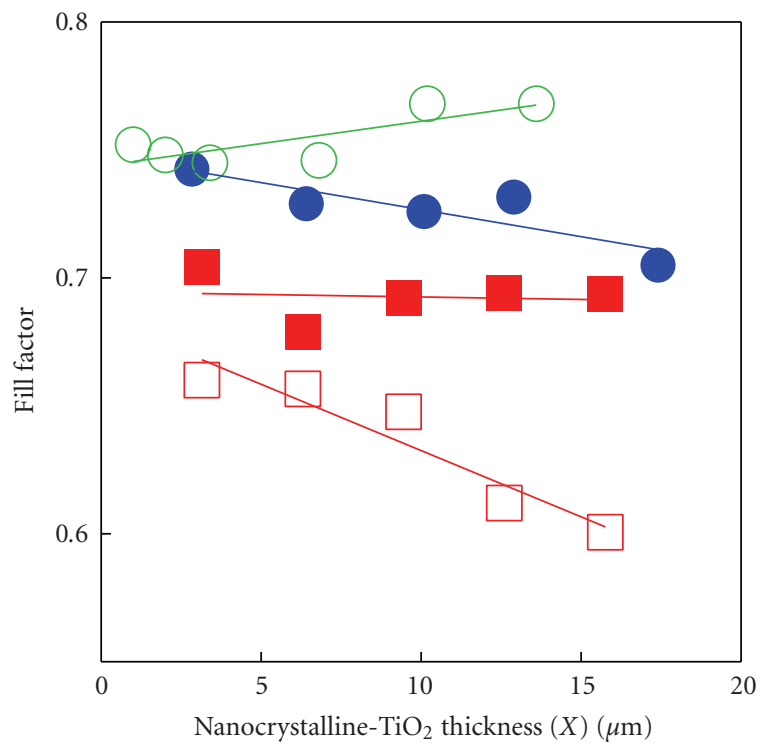

(c)

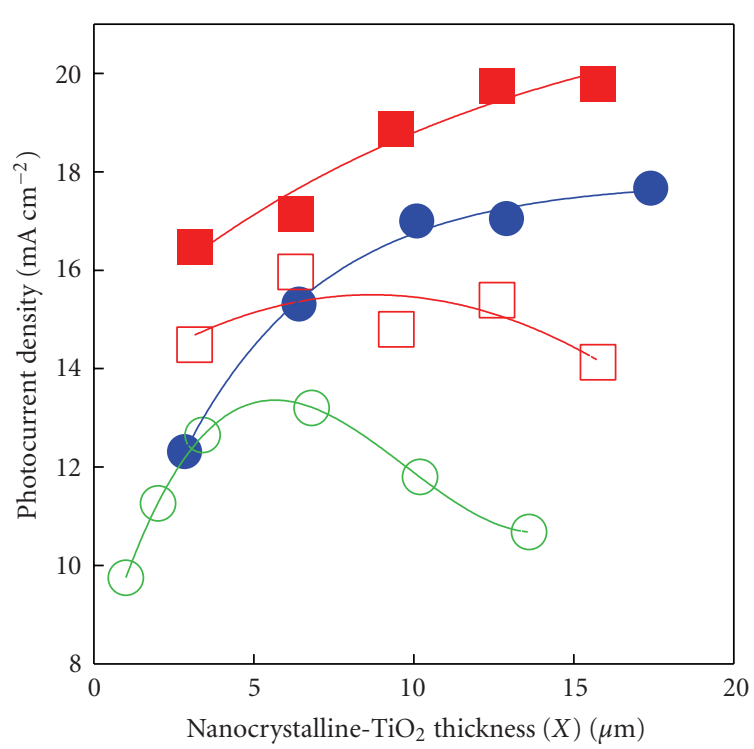

(b)

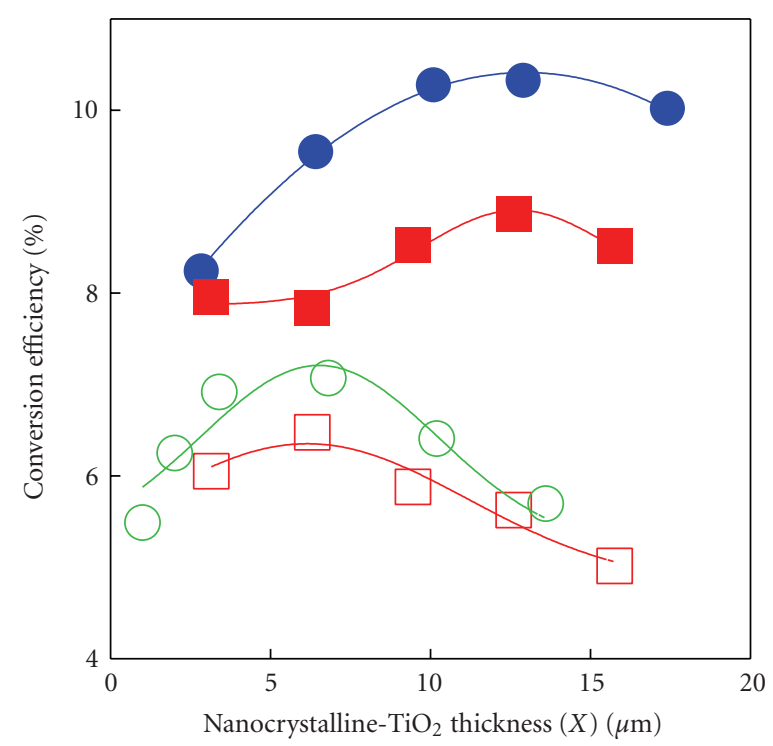

(d)

FIgure 7: Photovoltaic characteristics in relation to the thickness of nanocrystalline- $\mathrm{TiO}_{2}(d=20$ nm $)$ layers in double-layer electrodes (as shown in Figure 1(b)): N719-sensitized solar cells using AcCN-based electrolytes (solid circles); K19-sensitized solar cells using ionicliquid-based electrolytes (open circles); D149-sensitized solar cells using AcCN-based (solid square) and ionic-liquid-based (open square) electrolytes.

a high absorption coefficient that displays a strong blocking effect against charge recombination. We hope that this report is helpful for the development of DSCs for practical applications.

\section{Acknowledgments}

This work was supported by a grant from the Swiss Federal Energy Office (OFEN). The authors thank Mr. Tamotsu Horiuchi (Riko Co., Ltd., Japan) for assistance. The SEM cross-sectional views were obtained with the help of Dr. Mizuno (KOBELCO Co., Ltd., Japan).

\section{References}

[1] B. O’Regan and M. Grätzel, "A low-cost, high-efficiency solar cell based on dye-sensitized colloidal $\mathrm{TiO}_{2}$ films," Nature, vol. 353, no. 6346, pp. 737-740, 1991.

[2] M. Grätzel, "Photoelectrochemical cells," Nature, vol. 414, no. 6861, pp. 338-344, 2001.

[3] Y. Bai, Y. Cao, J. Zhang, et al., "High-performance dyesensitized solar cells based on solvent-free electrolytes produced from eutectic melts," Nature Materials, vol. 7, no. 8, pp. 626-630, 2008.

[4] S. Ito, S. M. Zakeeruddin, P. Comte, P. Liska, D. Kuang, and M. Grätzel, "Bifacial dye-sensitized solar cells based on an ionic 
liquid electrolyte," Nature Photonics, vol. 2, no. 11, pp. 693698, 2008.

[5] B. Wenger, M. Grätzel, and J.-E. Moser, "Rationale for kinetic heterogeneity of ultrafast light-induced electron transfer from $\mathrm{Ru}(\mathrm{II})$ complex sensitizers to nanocrystalline $\mathrm{TiO}_{2}$," Journal of the American Chemical Society, vol. 127, no. 35, pp. 1215012151, 2005.

[6] S. A. Haque, Y. Tachibana, D. R. Klug, and J. R. Durrant, "Charge recombination kinetics in dye-sensitized nanocrystalline titanium dioxide films under externally applied bias," Journal of Physical Chemistry B, vol. 102, no. 10, pp. 17451749, 1998.

[7] J. Bisquert, A. Zaban, M. Greenshtein, and I. Mora-Seró, "Determination of rate constants for charge transfer and the distribution of semiconductor and electrolyte electronic energy levels in dye-sensitized solar cells by open-circuit photovoltage decay method," Journal of the American Chemical Society, vol. 126, no. 41, pp. 13550-13559, 2004.

[8] S. Ito, P. Liska, P. Comte, et al., "Control of dark current in photoelectrochemical $\left(\mathrm{TiO}_{2} / \mathrm{I}^{-}-\mathrm{I}_{3}{ }^{-}\right)$and dye-sensitized solar cells," Chemical Communications, no. 34, pp. 4351-4353, 2005.

[9] S. Ito, T. N. Murakami, P. Comte, et al., "Fabrication of thin film dye sensitized solar cells with solar to electric power conversion efficiency over 10\%," Thin Solid Films, vol. 516, no. 14, pp. 4613-4619, 2008.

[10] S. Ito, N.-L. C. Ha, G. Rothenberger, et al., "High-efficiency (7.2\%) flexible dye-sensitized solar cells with Ti-metal substrate for nanocrystalline- $\mathrm{TiO}_{2}$ photoanode," Chemical Communications, no. 38, pp. 4004-4006, 2006.

[11] S. D. Burnside, V. Shklover, C. Barbé, et al., "Self-organization of $\mathrm{TiO}_{2}$ nanoparticles in thin films," Chemistry of Materials, vol. 10, no. 9, pp. 2419-2425, 1998.

[12] Md. K. Nazeeruddin, S. M. Zakeeruddin, R. HumphryBaker, et al., "Acid-base equilibria of (2,2'-bipyridyl-4,4'dicarboxylic acid)ruthenium(II) complexes and the effect of protonation on charge-transfer sensitization of nanocrystalline titania," Inorganic Chemistry, vol. 38, no. 26, pp. 6298 6305, 1999.

[13] P. Wang, S. M. Zakeeruddin, J. E. Moser, Md. K. Nazeeruddin, T. Sekiguchi, and M. Grätzel, "A stable quasi-solid-state dyesensitized solar cell with an amphiphilic ruthenium sensitizer and polymer gel electrolyte," Nature Materials, vol. 2, no. 6, pp. 402-407, 2003.

[14] D. Kuang, S. Ito, B. Wenger, et al., "High molar extinction coefficient heteroleptic ruthenium complexes for thin film dye-sensitized solar cells," Journal of the American Chemical Society, vol. 128, no. 12, pp. 4146-4154, 2006.

[15] T. Horiuchi, H. Miura, K. Sumioka, and S. Uchida, "High efficiency of dye-sensitized solar cells based on metal-free indoline dyes," Journal of the American Chemical Society, vol. 126, no. 39, pp. 12218-12219, 2004.

[16] S. Ito, S. M. Zakeeruddin, R. Humphry-Baker, et al., "Highefficiency organic-dye-sensitized solar cells controlled by nanocrystalline- $\mathrm{TiO}_{2}$ electrode thickness," Advanced Materials, vol. 18, no. 9, pp. 1202-1205, 2006.

[17] S. Ito, Md. K. Nazeeruddin, P. Liska, et al., "Photovoltaic characterization of dye-sensitized solar cells: effect of device masking on conversion efficiency," Progress in Photovoltaics, vol. 14, no. 7, pp. 589-601, 2006.

[18] S. Ito, H. Matsui, K.-I. Okada, et al., "Calibration of solar simulator for evaluation of dye-sensitized solar cells," Solar Energy Materials and Solar Cells, vol. 82, no. 3, pp. 421-429, 2004. 


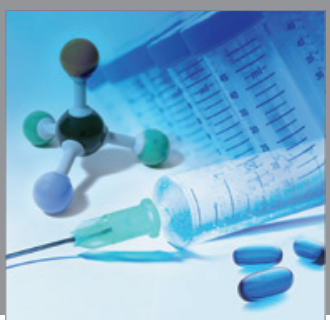

International Journal of

Medicinal Chemistry

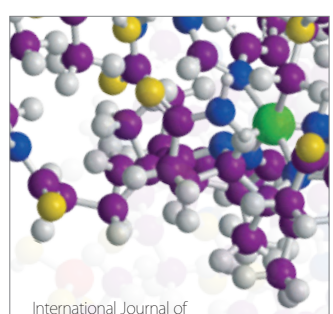

Carbohydrate Chemistry

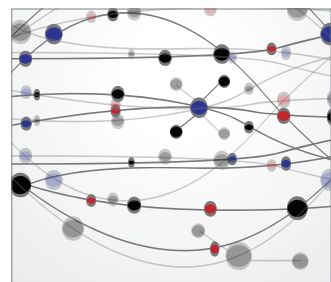

The Scientific World Journal
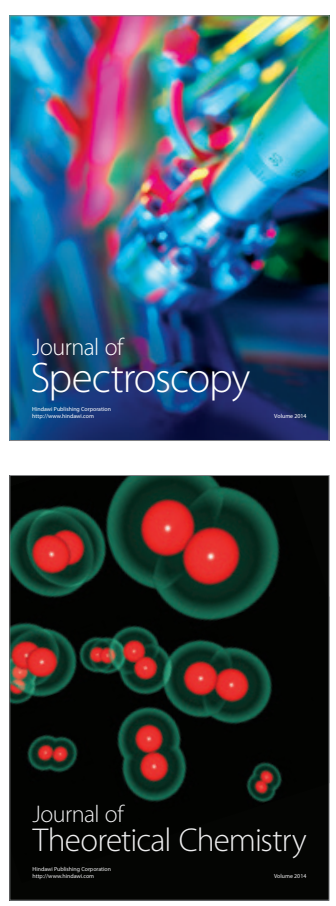
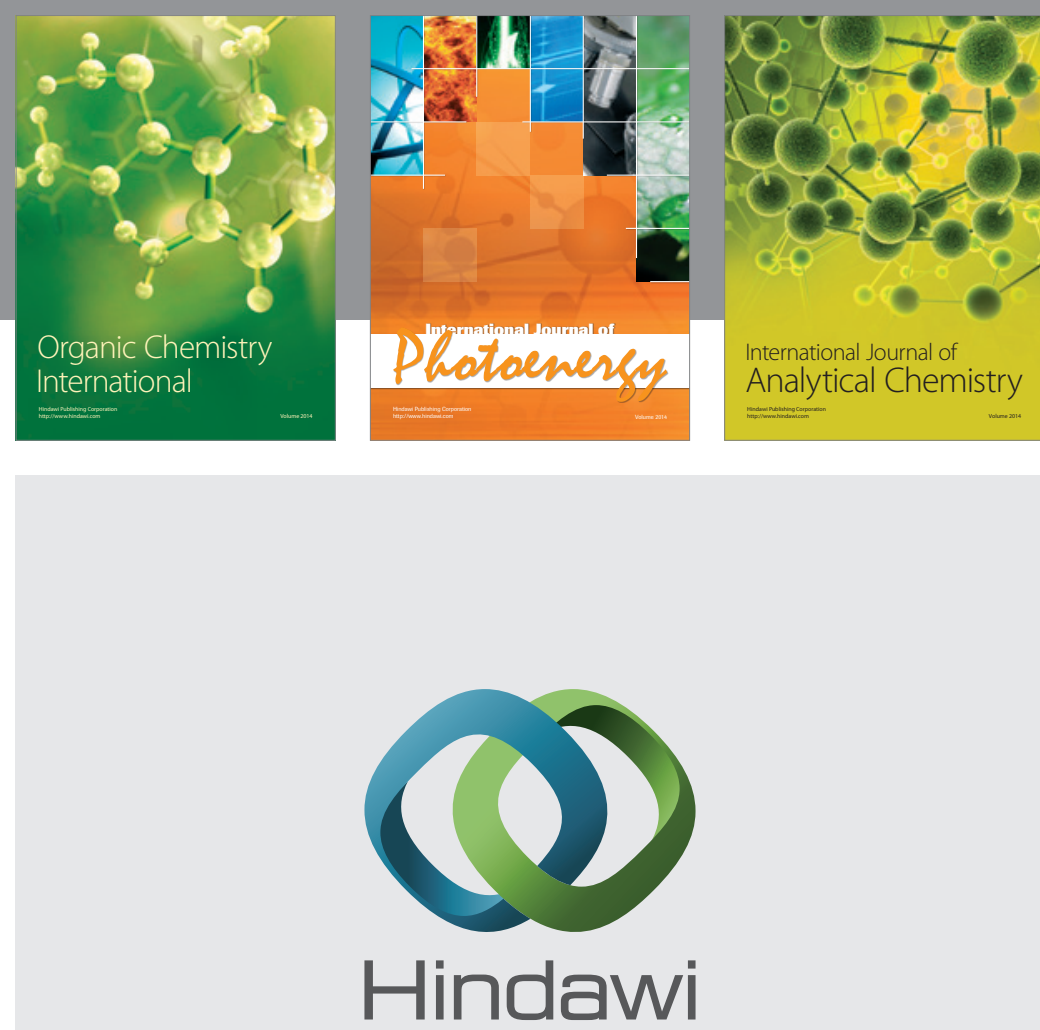

Submit your manuscripts at

http://www.hindawi.com
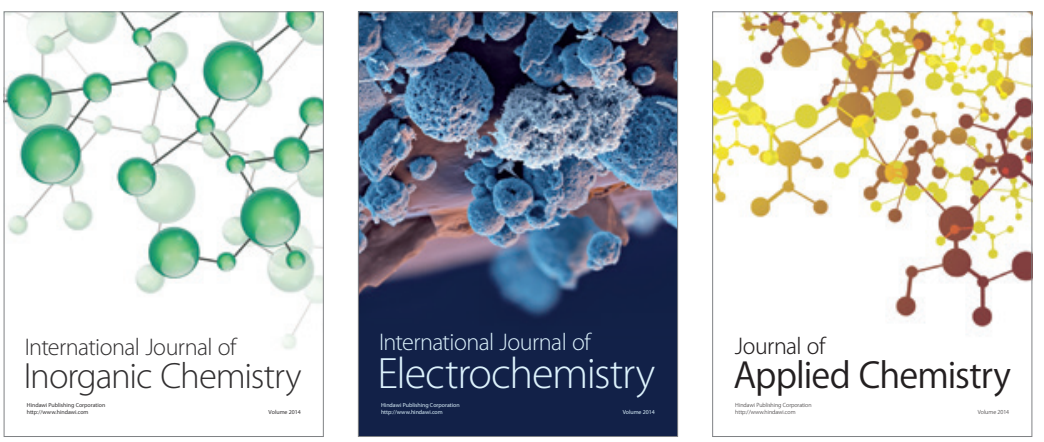

Journal of

Applied Chemistry
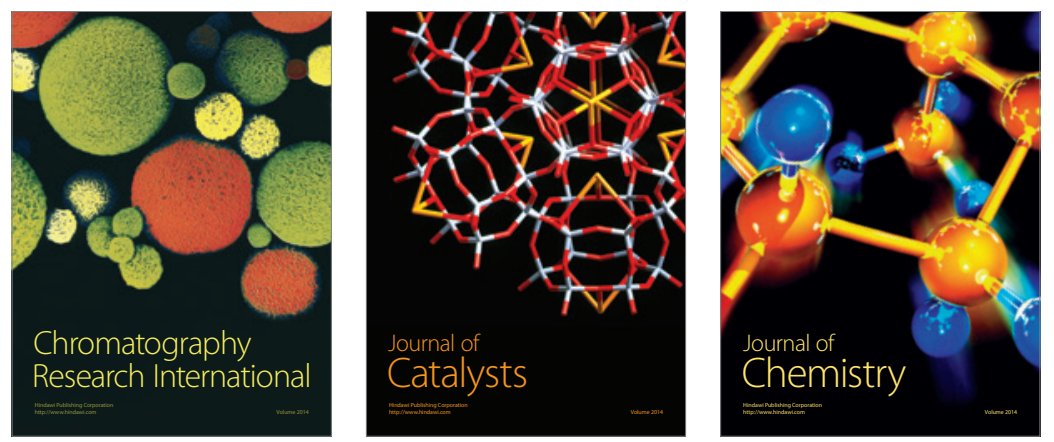
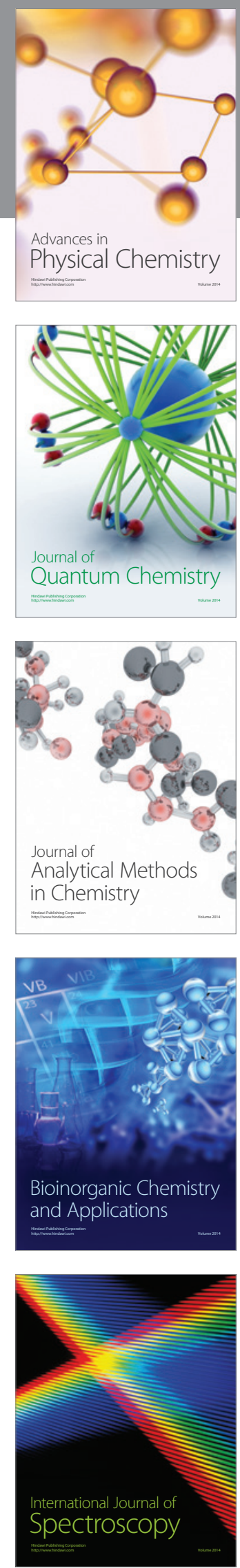